\title{
Prostaglandin-Induced Resorption of the Adult Rat Calvarium
}

\section{J. MAX GOODSON, KENNETH MCCLATCHY and CLIFFORD REVELL}

School of Dentistry, University of California, San Francisco, California 94143, USA; University of Michigan Medical Center, Ann Arbor, Michigan 48104, and University of Alberta, Faculty of Dentistry, Edmonton, Alberta, Canada

Prostaglandin $E_{1}$-containing solutions injected under the skin overlying the calvarium of adult rats produced a visible resorptive lesion within the bone in seven days. The resorptive process was characterized by $\mathrm{f}$ brous replacement of bone matrix and by increased vascularity. Inflammatory cells were not apparent.

Prostaglandins are a family of naturally occurring fatty acids that participate in the inflammatory process ${ }^{1-4}$ and exhibit hormonelike effects. 5,6 When prostaglandins are injected intradermally, they produce local inflammatory effects such as increased vascular permeability with edema and vasodilatation with erythema. ${ }^{7,8}$ They have been identified in inflammatory exudates ${ }^{9-11}$ and their biosynthesis is inhibited by nonsteroidal anti-inflammatory drugs. ${ }^{12-15}$

The prostaglandins $\mathrm{PGE}_{1}, \mathrm{PGE}_{2}$, and to a lesser extent $\mathrm{PGF}_{2} \alpha$ stimulate resorption of cultured fetal rat bones. ${ }^{16.17}$ In these systems E-type prostaglandins are more potent than is parathyroid hormone in producing bone resorption, although osteolytic action occurs at a slower rate. The action of the E-type prostaglandins and parathyroid hormone is accompanied by elevation of bone cyclic $3 '-5^{\prime}$ adenosine monophosphate. ${ }^{18}$

When they are injected systematically, prostaglandins are rapidly metabolized ${ }^{19,20}$ by 15 dehydrogenation and by reduction of the 13-14 double bond (Fig l). The biologic activity of the metabolic products is reduced substantially.

Because of the rapid inactivation and low

This investigation was supported in part by the USPHS Grant No. DE03286 from the National Institute of Dental Research, National Institutes of Health, Bethesda, Md and by a grant from the California Dental Association.

Received for publication December 11, 1972. blood levels, and since large doses of prostaglandins that are injected intraperitoneally fail to produce elevated blood calcium in parathyroidectomized rats, ${ }^{16}$ prostaglandins do not normally participate as blood-borne humoral elements that regulate calcium metabolism like the parathyroid hormone. However, this does not preclude a role in the production of localized osteolytic lesions. Since most forms of periodontal disease are associated with inflammation and extensive loss, the participation of prostaglandins in this disease process should be considered.

The purpose of this paper is to describe morphologic alteration that is produced by prostaglandin injection over bone surfaces of the adult rat and to discuss the possible relevance of this process to periodontal disease.

\section{Materials and Methods}

The effect of prostaglandins on bone morphology was investigated in $250 \mathrm{gm}$ adult male Sprague-Dawley rats. Solutions or suspensions that contained prostaglandins were injected over the calvaria.

Injections were made with a 0.25 -ml tuberculin syringe by penetration of the skin with a 26-gauge, half-inch needle at a point midway between the eyes; the needle passed parallel to the skull in the direction of the calvarium. The solution was deposited over

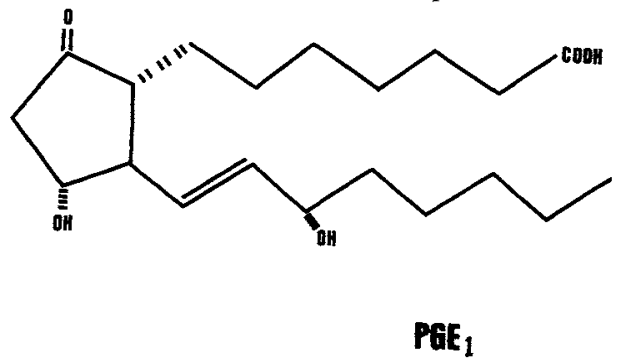

FIG 1.-Chemical structure of prostaglandin $\mathbf{E}_{1}$. 
the periosteal surface of the frontal and parietal bones $-1.5 \mathrm{~cm}$ posterior to the junction of the zygomatic arch and the maxilla. The rats were anesthetized with light ether.

Glycerol, saline, peanut oil, and agar were tested as vehicles. Solutions for injection were made from a concentrated stock $\mathrm{PGE}_{1}$ solution $(10 \mu \mathrm{g} / \mu \mathrm{l})$ that was prepared by adding $1 \mathrm{ml}$ ethanol to $10 \mathrm{mg} \mathrm{PGE}{ }_{1}{ }^{a}$ Glycerol, saline, and peanut oil solutions were made by pipetting $50 \mu \mathrm{l}$ of stock into $500 \mu \mathrm{l}$ of vehicle. Fifty-five microliters of this solution containing $50 \mu \mathrm{g} \mathrm{PGE}_{1}$ was injected. Control rats were injected similarly with a solution containing $50 \mu \mathrm{l}$ of vehicle and 5 $\mu l$ of ethanol. Early prostaglandin effects were studied in six animals that were killed in pairs after one, three, and five daily injections of $\mathrm{PGE}_{1}$ in glycerol.

The use of agar as a vehicle was tested in four rats. A $1 \%$ agar solution ${ }^{b}$ was made by heating it to $100 \mathrm{C}$. The agar was cooled to $60 \mathrm{C}$ and $\mathrm{PGE}_{1}$ in ethanol was added. The ethanol evaporated rapidly leaving a suspension of $\mathrm{PGE}_{1}$ crystals in agar. Fifty microliters of this suspension containing 100 $\mu \mathrm{g} \mathrm{PGE}_{1}$ was injected with a warmed $0.25-\mathrm{ml}$ tuberculin syringe and a 26 -gauge needle over the calvaria of two rats. Two control rats were injected similarly with agar alone.

Injection parameters for calvaria experiments are listed in the Table. Rats were injected daily and they were killed with an overdose of pentobarbital sodium. The calvaria from half of the rats were prepared for histological observation by fixation in a $10 \%$ $\mathrm{w} / \mathrm{v}$ formaldehyde solution and they were decalcified in a $6 \mathrm{~N}$ formic acid solution with 0.3 sodium citrate for seven days. Decalcified tissues were embedded in paraffin, sectioned at 5 micrometers $(\mu \mathrm{m})$, stained with hematoxylin and eosin, and photographed. Early effects were investigated histologically only. The remainder of the skulls were defleshed by boiling to observe macroscopic changes in the superficial bone morphology.

Prostaglandin effects on alveolar bone were also investigated. A concentrated suspension of $\mathrm{PGE}_{1}$ in glycerol was prepared for injection in the alveolar region of two rats. The suspension was injected with a $10-\mu \mathrm{l}$ syringec that is capable of handling high viscosity liquids. Five microliters containing $50 \mu \mathrm{g}$

\footnotetext{
a Upjohn Corp., Kalamazoo, Mich.

b Difco Laboratories, Detroit, Mich.

c Hamilton No. 701, Reno, Nev.
}

TABLE

SOlutions In Jected OVER THE Calvarium of ADULt Rats

\begin{tabular}{cccc}
$\begin{array}{c}\text { Daily PGE } \\
\text { Dose }(\mu \mathrm{g})\end{array}$ & $\begin{array}{c}\text { No. of } \\
\text { Injec- } \\
\text { tions* }\end{array}$ & $\begin{array}{c}\text { No. of } \\
\text { Rats }\end{array}$ & Vehicle \\
\hline 50 & 7 & 10 & $50 \mu \mathrm{l}$ glycerol and \\
0 & 7 & 10 & $5 \mu \mathrm{l}$ ethanol \\
50 & 7 & 2 & $50 \mu \mathrm{l}$ saline and \\
0 & 7 & 2 & $5 \mu 1$ ethanol \\
50 & 7 & 2 & $50 \mu \mathrm{l}$ peanut oil and \\
0 & 7 & 2 & $5 \mu 1$ ethanol \\
100 & $\mathrm{I}$ & 2 & $50 \mu 1$ agar \\
0 & 1 & 2 & \\
50 & 1 & 1 & $50 \mu 1$ glycerol and \\
0 & 1 & 1 & $5 \mu l$ ethanol \\
50 & 3 & 1 & \\
0 & 3 & 1 & \\
50 & 5 & 1 & \\
0 & 5 & 1 &
\end{tabular}

- Rats were killed one day after their last injection; animals that received agar injections were killed seven days after the single injection.

$P G E_{1}$ was injected daily for seven days over the alveolar bone on the distal surface of the mandibular incisors. On the eighth day, the mandible was removed for histological processing. Control injections of glycerol were made on the contralateral side. Tissues were prepared for histology as were the calvaria.

\section{Results}

After seven days of repeated injection of $50 \mu \mathrm{g} \mathrm{PGE} \mathrm{P}_{1}$ in glycerol, gross inspection of the injection site showed a localized area of highly vascular connective tissue. When the skull was boiled to remove soft tissue, a roughened area was observed on the calvarial surface beneath the site of prostaglandin injection in all the experimental rats; (Fig 2,top). This was not seen in rats that were injected with vehicle alone (Fig 2, bottom).

Low power observation of decalcified sections of prostaglandin-treated calvaria shows extensive loss of bone matrix and fibrous replacement (Fig 3, top). Calvaria from animals that were injected with the vehicle alone exhibited a subcutaneous fibrous reaction and some hemorrhage at the injection site; however no erosion of the bone surface was present (Fig 3, bottom). 

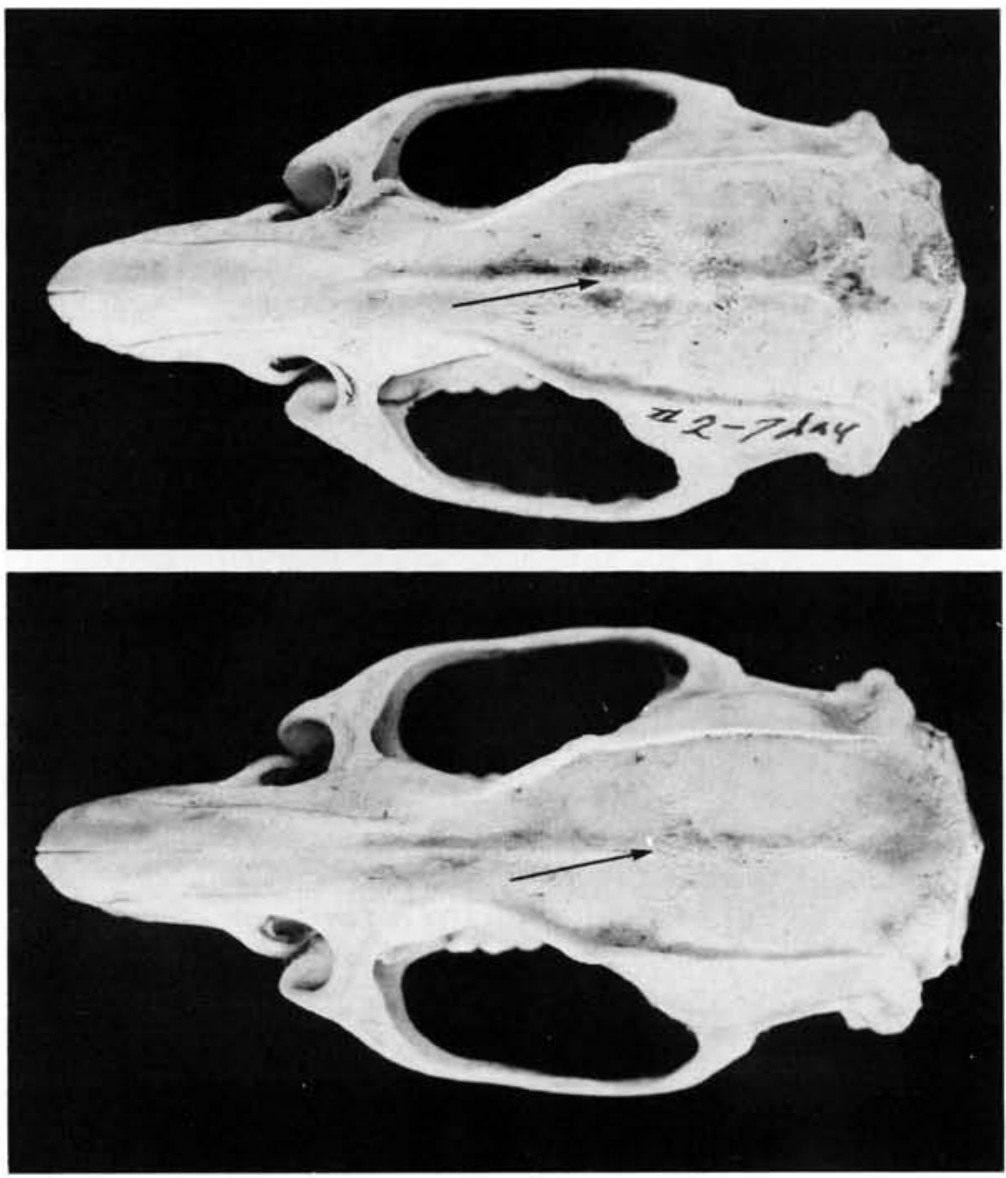

FIG 2.-Macroscopic appearance of the calvarium of an adult rat. Top, after repeated injection of $\mathrm{PGE}_{1} ;$ bottom, after repeated injection of vehicle.

Microscopic examination of uninjected rat calvaria showed a dense bone matrix that was covered by a thin periosteal layer and loose subcutaneous connective tissue (Fig 4). The bone matrix had a regular lamellar structure that ran parallel to the bone surface. The matrix contained occasional small osteocytes at irregular intervals. The periosteal layer showed thin cells with flattened nuclei. The subcutaneous connective tissue contained few cellular or formed elements. Repeated injections of glycerol produced a fibrous reaction in the connective tissue, but no effect on the bone matrix was seen (Fig 5) .

An altered morphology of the periosteal cells was observed after prostaglandin injection. Cells of the periosteal layer seemed enlarged one day after a single injection of $50 \mu \mathrm{g} \mathrm{PGE}_{1}$ (Fig 6). Formerly flat nuclei seemed rounded and hyperchromatic. Areas of the bone matrix along the periosteal surface were irregular. There was an increased cellularity in the subcutaneous connective tissue layer.

During the course of repeated daily prostaglandin injections, a higher degree of bone matrix irregularity appeared. After three days of repeated injection, the laminar pattern was partially interrupted and blood vessels were more numerous in the subcutaneous connective tissue (Fig 7). In addition to the erosive pattern that is usually seen, areas were found where new growth occurred as irregular outcroppings from the original laminar surface (Fig 8). These growths occurred most often toward the periphery of the injection site.

Seven days after a single injection of 100 $\mu \mathrm{gGE}_{1}$ in agar, a bone lesion similar to the 

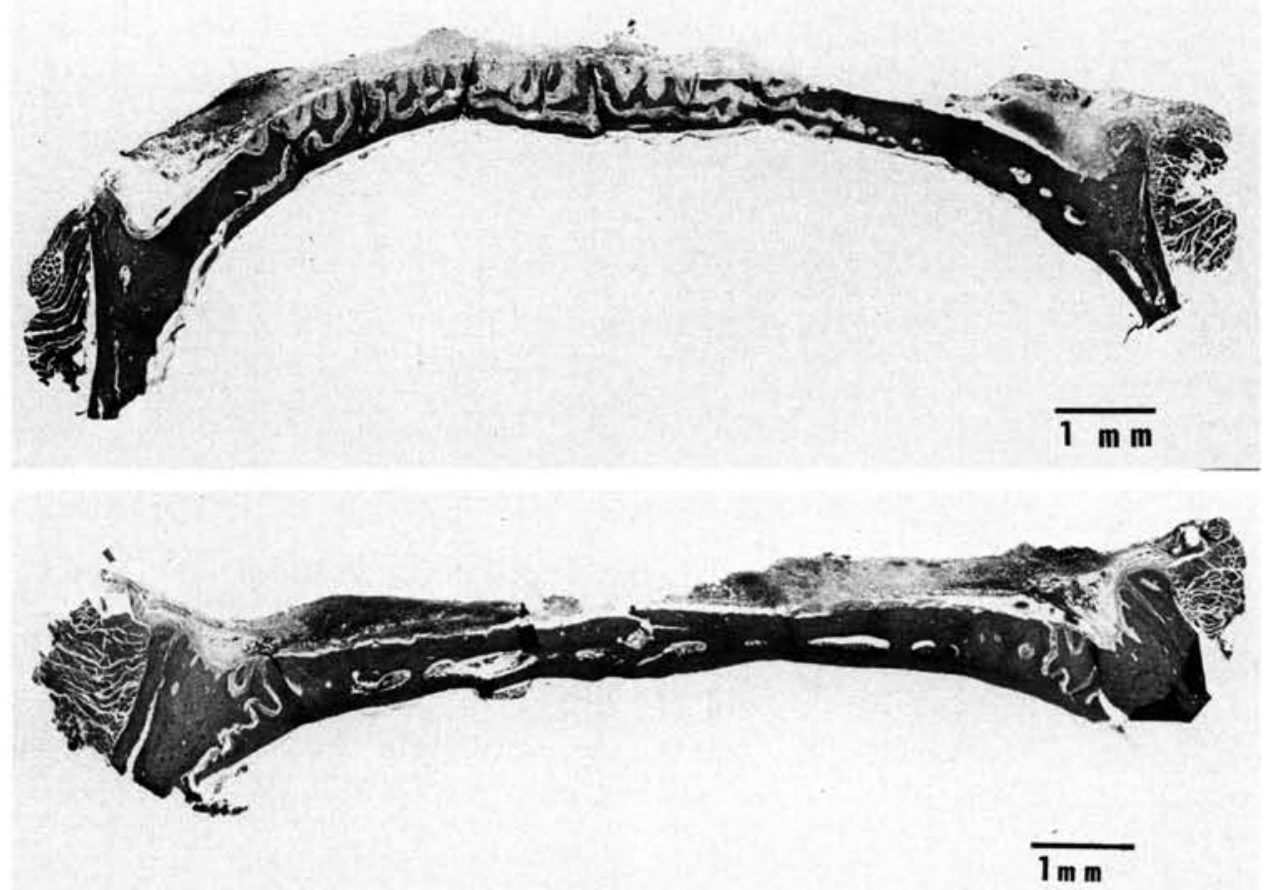

FIG 3.-Low power cross section of decalcified calvaria from prostaglandin-injected (top) and glycerol-injected (bottom) rats.

lesion seen after seven days of repeated $\mathrm{PGE}_{1}$ injection was produced (Fig 9). In this instance the injection artifact was minimal in that no area that was injected with agar alone differed substantially from the calvaria of uninjected rats. The most prominent effect was an extensive loss of bone matrix, which had been replaced by cellular connective tissue. Many blood vessels appeared in the cellular stroma surrounding

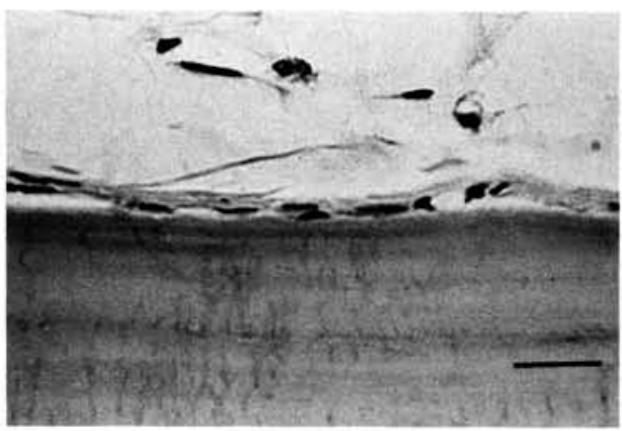

Fig 4-Calvarial surface of uninjected rat (calibration $=50 \mu \mathrm{m}$ ) . isolated bone spicules. The resorbing surfaces of the bone matrix (Fig 10) were lined predominantly with uninuclear cells with dark-staining nuclei. These cells were found often in lacunae. Osteocytes seemed somewhat enlarged and prominent within the remaining bone matrix. The lamellar structure of several areas was disrupted; in some cases it departed frim the original parallel structure. Multinucleated cells were infre-

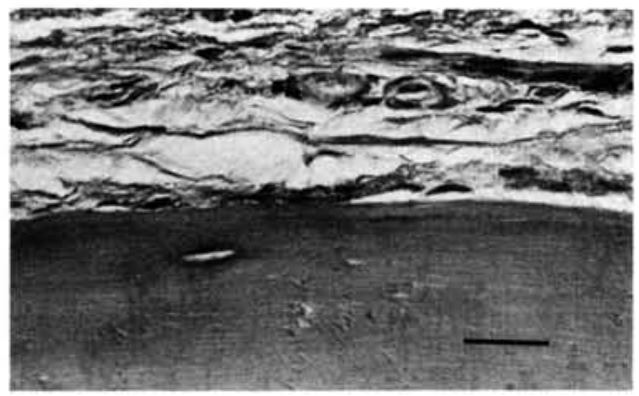

FIG 5.-Calvarial surface after seven days of repeated injection of glycerol vehicle (calibration $=50 \mu \mathrm{m})$. 


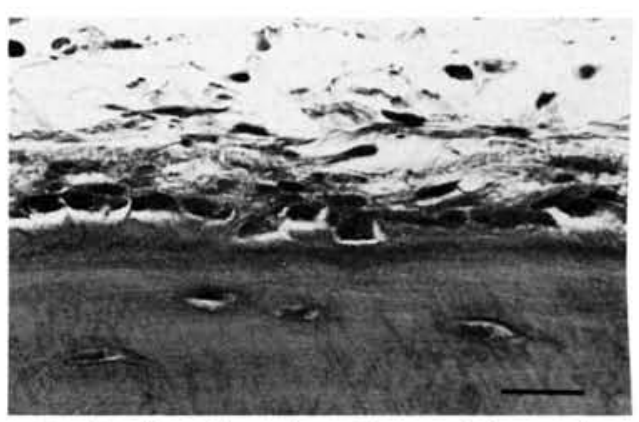

Fig 6.-Altered periosteal morphology along calvarial surface after a single injection of $\mathrm{PGE}_{1}$ (calibration $=50 \mu \mathrm{m}$ ) .

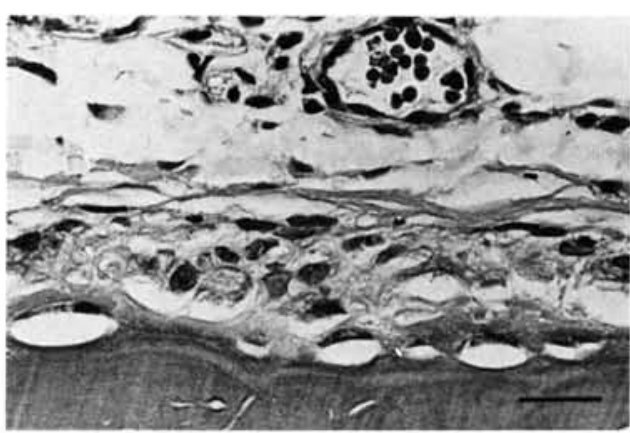

Fig 7.-Disrupted lamellar contour on calvarial surface after three daily injections of PGE (calibration $=50 \mu \mathrm{m}$ ) .

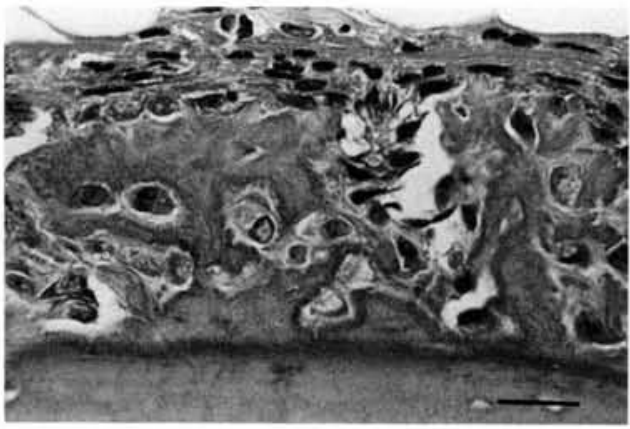

Fig 8.-Irregular bone matrix outcroppings observed in some areas on calvarial surface after five daily injections of $\mathrm{PGE}_{1}$ (calibration $=50$ $\mu \mathrm{m})$.

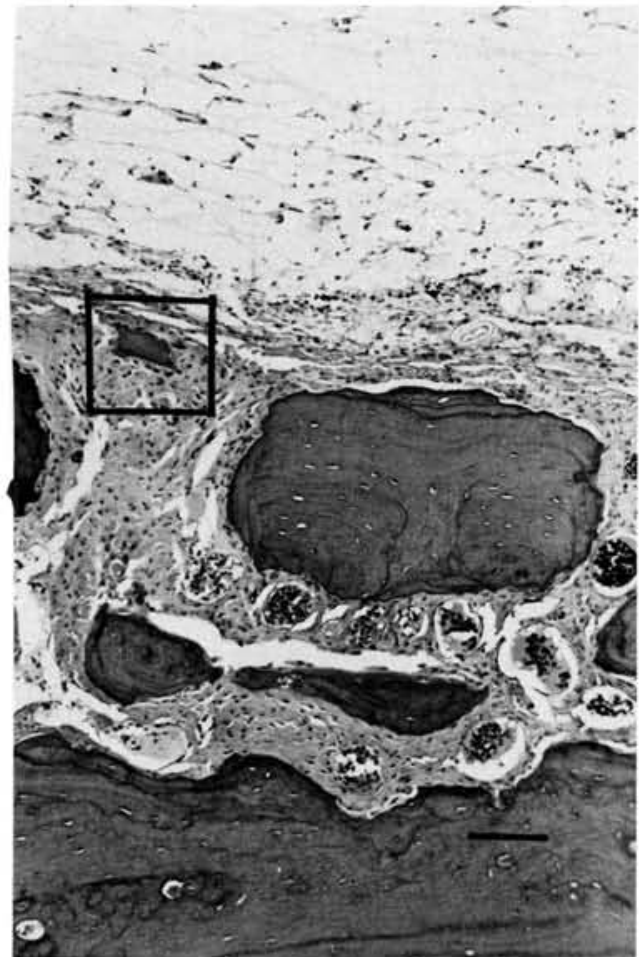

Fig 9.-Surface of rat calvarium injected with $100 \mu \mathrm{g} \mathrm{PGE}_{1}$ in agar after seven days (calibration $=200 \mu \mathrm{m}$ ).

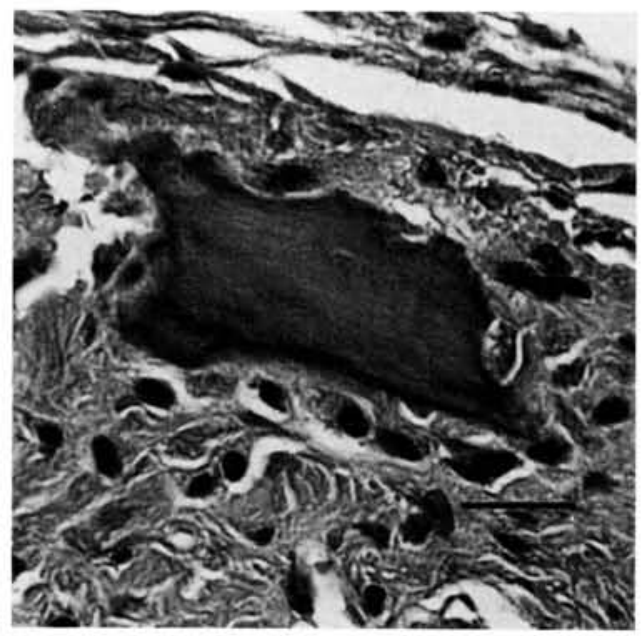

FIG 10.-Enlargement of boxed area in Figure 9. Extensive resorption of bone matrix results in formation of isolated bone spicules (calibration $=50 \mu \mathrm{m}$ ). 


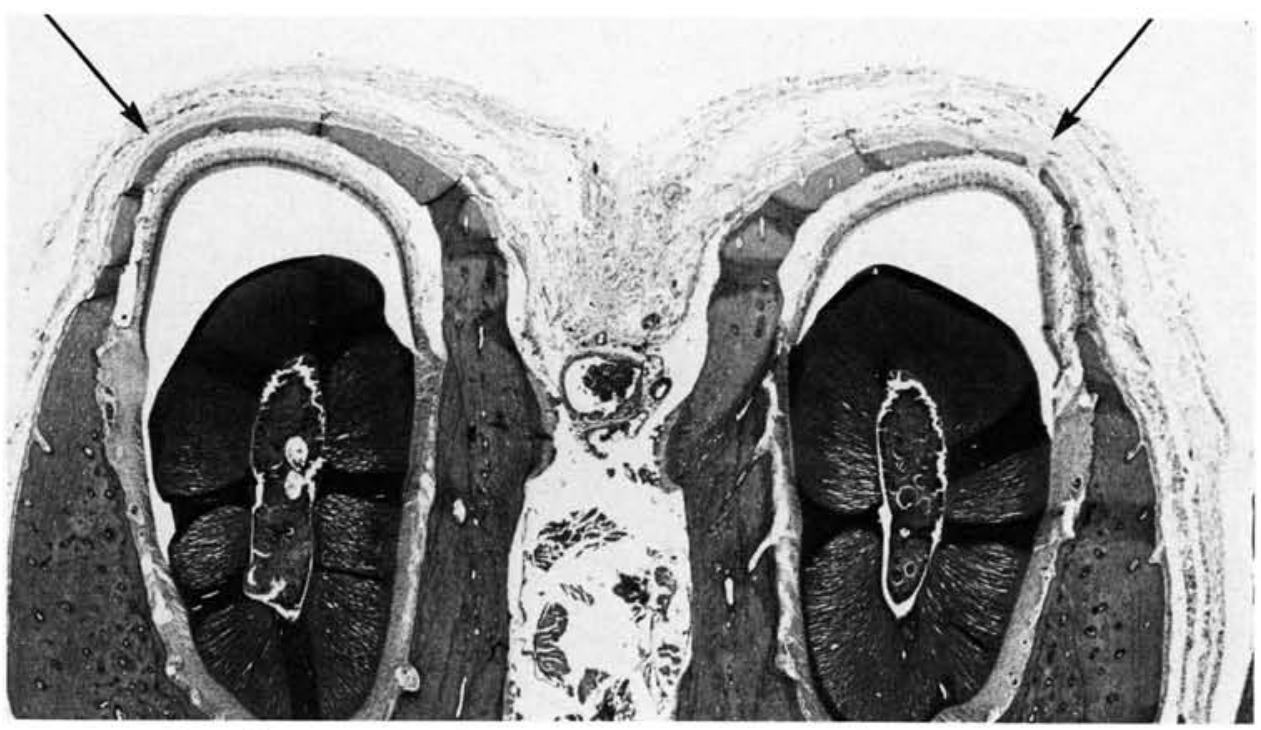

FIG 11.-Effect of $\mathrm{PGE}_{1}$ injected over rat alveolar bone (right arrow) as compared with vehicle injection site (left arrow).

quently observed. No signs of leukocyte infiltration or exudate formation were apparent.

Repeated injection of $\mathrm{PGE}_{1}$ containing suspension over rat alveolar bone produced a resorptive pattern similar to that which was seen in the calvaria. A low magnification view from a section that was taken parallel to the mandible through the incisors at the injection site showed discontinuity in the alveolar plate on the side of the $\mathrm{PGE}_{1}$ injection. Higher magnification views (Fig 12) showed that the bone at the $\mathrm{PGE}_{1}$ injection site seemed to be partially resorbed and replaced by cellular connective tissue. This discontinuity was not seen on the side that was injected with glycerol (Fig 11).

Saline and peanut oil were inferior to glycerol as vehicles. Prostaglandin solutions in saline were not effective in producing a bone lesion. Prostaglandin solutions in peanut oil produced a bone lesion; however, animals that were injected with the vehicle alone showed a similar but smaller lesion.

\section{Discussion}

Prostaglandin administration did not mimic the periodontal disease process but there are at least three aspects in which
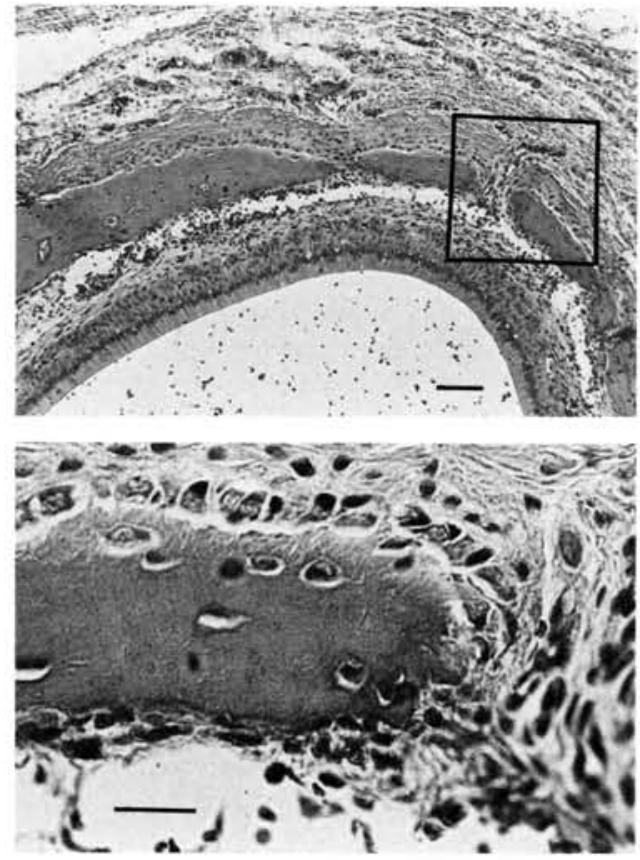

Fig 12.-Top, higher power view of alveolar bone discontinuity on side of $\mathrm{PGE}_{1}$ injection (calibration $=50 \mu \mathrm{m}$ ). Bottom, enlargement of boxed area shows cellular detail of bone spicules apparently undergoing resorption at $\mathrm{PGE}_{1}$ injection site (calibration $=50 \mu \mathrm{m})$. 
prostaglandin-induced bone resorption resembled that of the disease. ${ }^{21}$ It involved the action of live cells on viable bone; resorbing surfaces were sculptured with covelike lacunae; and there was a strong suggestion of vascular component to the resorption process.

Prostaglandin-induced bone resorption differed from the histological appearance of periodontal disease in its absence of inflammatory cells. However, there is considerable evidence that oral bacteria stimulate the formation of chemotactic factors. ${ }^{22}$ This could account for the inflammatory cell infiltration that is characteristic of periodontal disease. Leukocytes may be especially important in this connection because there is evidence that they release prostaglandins ${ }^{23}$ and another osteolytic principle. ${ }^{24}$

Prostaglandins are slightly chemotactic. ${ }^{3}$ The absence of a significant infiltration of inflammatory cells at the site of prostaglandin injection indicated a negligible chemotactic effect in the rat subcutaneous connective tissue. Furthermore, this finding indicated that bacterial inflammation was not introduced inadvertently as a result of the injection procedure.

Increased vascularity associated with bone resorption was observed commonly. Although the vasodilator action of prostaglandins is well known, 5 stimulation of new blood vessel formation with chronic administration has not been studied. Under the conditions of these experiments, it cannot be ruled out that increased vascularity could have been mediated indirectly by products of the resorptive process.

The concentration of $\mathrm{PGE}_{1}$ that was used in this study $(3 \mathrm{mM})$ was greater than the levels that occur in tissue. Failure of saline as a vehicle suggests that washout is relatively rapid; this is expected of a vasodilator substance.

\section{Conclusions}

A subcutaneous injection of prostaglandin $E_{1}$ over a bone surface stimulated rapid resorption of bone matrix in the adult rat. The earliest morphologic alterations observed were associated with the fibroblasts of the periosteal layer. As the resorptive process continued, areas of resorbed bone matrix developed. Cellular connective tissue containing newly formed vascular elements replaced the former bone matrix. Some areas showed signs of irregular formation of new bone. In- flammatory cells were absent and multinucleated osteoclasts were uncommon.

The rapidity and extent to which bone resorption was produced by prostaglandin injection suggests that a local synthesis of lesser amounts over a longer period of time could account for the bone loss in localized bone-wasting diseases. The recent elucidation of prostaglandins as inflammatory mediators offers a plausible hypothesis for their genesis in periodontal disease.

\section{References}

1. BrocklehURst, W.E.: Role of Kinins and Prostaglandins in Inflammation, Proc $R$ Soc Med 64: 4-6, 1971.

2. Hinman, J. W.: Prostaglandins, Ann Rev Biochem 41: 161-178, 1972.

3. KALEY, G., and WeINeR, R.: Prostaglandin $E_{1}$ : A Potential Mediator of the Inflammatory Response, Ann NY Acad Sci 180:338350,1971 .

4. Willoughiy, D.A.: The Inflammatory Response, J Dent Res 51: 226-227, 1972.

5. Bergstrom, S.; Carlson, L.A.; and Weeks, J.R.: The Prostaglandins: A Family of Biologically Active Lipids, Pharmacol Rev 20: $1-48,1968$.

6. Horton, E.W.: Hypotheses on Physiological Roles of Prostaglandins, Physiol Rev 49: 122 . 161, 1969.

7. Solomon, L.M.; Juhlin, L.; and KirchenBaUm, M.B.: Prostaglandins on Cutaneous Vasculature, J Invest Dermatol 51:280-282, 1968.

8. Sondergand, J., and Greaves, M.W.: Prostaglandin $E_{1}$ : Effect on Human Vascuiature and Skin, Br J Dermatol 84: 424, 1971.

9. WILLIs, A.L.: Identification of Prostaglandin $\mathbf{E}_{2}$ in Rat Inflammatory Exudate, Pharmacol Res Comm 2: 297-304, 1970.

10. Willis, A.L.: Parallel Assay of Prosta. glandin-like Activity in Rat Inflammatory Exudate by Means of Cascade Superfusion, I Pharm Pharmacol 21: 126-128, 1969.

11. ÄNGGARD, E., and JohNson, C.: Formation of Prostaglandins in the Skin Following a Burn Injury in Ramwell, D.W., and FerRIS, B.B. (eds) : Prostaglandins in Cellular Biol. ogy and the Inflammatory Process, New York: Plenum Press, 1972, pp 269-284.

12. VANE, J.R.: Inhibition of Prostaglandin Synthesis as a Mechanism of Action for Aspirinlike Drugs, Nature [New Biol] 231: 232-235, 1971.

13. Smith, J.B., and Willis, A.L.: Aspirin Selectively Inhibits Prostaglandin Production in Human Platelets, Nature [New Biol] 231: 235-237, 1971.

14. Ferreira, S.H.; Moncada, S.; and Vane, J.R.: Indomethacin and Aspirin Abolish 
Prostaglandin Release from the Spleen, $\mathrm{Na}$ ture [New Biol] 231: 237-239, 1971.

15. Collier, H.O.: Prostaglandin and Aspirin, Nature (Lond) 232: 17-19, 1971.

16. Klein, D.C., and Raisz, L.G.: Prostaglandins: Stimulation of Bone Resorption in Tissue Culture, Endocrinology 86: 1436-1440, 1970.

17. Voekel, E.F.; TASHJian, A.H.; and Goldhaber, P.: A Non-peptide Produced by Fibrosarcoma Cells that Stimulates Bone Resorption in Organ Culture, in Calcium, Parathyroid Hormone and the Calcitonins, in Talmage, R.V., and Munson, P.L. (eds) : Excerpta Medica, Amsterdam, 1972.

18. Auerbach, G.D., and Chase, L. R.: Cyclic 3' 5' Adenylic Acid in Bone and the Mechanism of Action of Parathyroid Hormone, Fed Proc 29: 1179-1182, 1970.

19. Ferreira, S.H., and VANe, J.R.: Prostaglandins: Their Disappearance from and Release into the Circulation, Nature (Lond) 216: 868,1970 .
20. Samuelsson, B.; Granstrom, E.; Green, K.; and HAMBERG, M.: Metabolism of Prostaglandins. Ann NY Acad Sci 180: 138-161, 1971.

21. Glickman, I., and Woon, H.: Bone Histology in Periodontal Disease, $J$ Dent Res 21 : $35-54,1942$.

22. Mergenhagen, S.E.; Tempel, T.R.; and SNyderman, R.: Immunologic Reactions and Periodontal Inflammation, J Dent Res 49: 256-267, 1970.

23. Movat, H. Z.; Macmorine, D.R.L.; and Takeuchi, T.: The Role of PMN-Leucocyte Lysosomes in Tissue Injury, Inflammation and Hypersensitivity, Int Arch Allergy Appl Immunol 40:218-235, 1971.

24. Horton, J.E.; Raisz, L.G.; Simmons, A.A.; Oppenheim, J.J.; and Mergenhagen, S.E.: Bone Resorbing Activity in Supernatant Fluid from Cultured Human Peripheral Blood Leucocytes, Science 177: 793-795, 1972. 